\title{
Static Voltage Stability Investigations on a Part of a Transmission Grid
}

\author{
Csaba Farkas ${ }^{1}$, Andor Faludi ${ }^{1}$, Tamás Decsi ${ }^{2}$
}

\begin{abstract}
Reliable power supply is crucial for all the industrial and household consumers, but the voltage-preserving capability might decrease at certain parts of the grid because of reduced reactive power generation, as conventional generating units are out of operation. It is very important to investigate, whether this weakened grid can still supply the customers even under stressed operating conditions. We used the PV analysis capability of PSS/E software to investigate the voltage stability of a 50 bus model for various contingency situations. Voltage stability investigations show what the limits of power supply with low reactive power generating capacity inside the investigated area and under pre-specified stressed operating conditions are. The investigated grid has limited internal generating capacity, most of the real and reactive power comes from outer sources: simulations have also been conducted to investigate how various contingencies and import scenarios affect system losses.
\end{abstract}

Keywords

PSS/E, PV analysis, static voltage stability, system losses

\footnotetext{
${ }^{1}$ Department of Electric Power Engineering Faculty of Electrical Engineering and Informatics, Budapest University of Techology and Economics H-1111 Budapest, Egry József str. 18. (e-mail: farkas.csaba@vet.bme.hu, faludi.andor@vet.bme.hu)

${ }^{2}$ MAVIR Hungarian Independent Transmission Operator Company,

H-1031 Budapest, Anikó str. 4., Hungary (e-mail: decsit@mavir.hu)
}

\section{Introduction}

Voltage instability is becoming a common problem in power systems (in fact, it is as important as thermal overload and angle instability problems [1]): it is wellknown that new generating and transmission units are difficult to install, the number of voltage controlled busbars is decreased, while the existing system is operated close to its limits, mostly due to economical reasons. This is why it is very important to determine these operating limits, "in particular, with respect to voltage instability" [1].

The aim of this paper is to give a description of the voltage stability phenomena through quantitative analysis. In Section 2. and 3. we give a brief summary about voltage stability and PV analysis; the rest of the paper deals with the simulation results. We investigated a grid composed of 50 busbars that resembles to a certain part of the Hungarian transmission system (see Fig. 3.). PV simulations were conducted using PSS/E software. For automated runs and system loss calculations, various program codes were written in Python, utilizing the builtin PSS/E module PSSPY.

\section{Voltage stability}

Fig. 1. depicts the basics of electric power transmission on a simple grid with two busbars [1]:

This is an Open Access article distributed in accordance with the Creative Commons Attribution Non Commercial (CC-BY-NC-ND 4.0) license, which permits others to copy or share the article, provided original work is properly cited and that this is not done for commercial purposes. Users may not remix, transform, or build upon the material and may not distribute the modified material (http://creativecommons.org/licenses/by-nc/4.0/) 


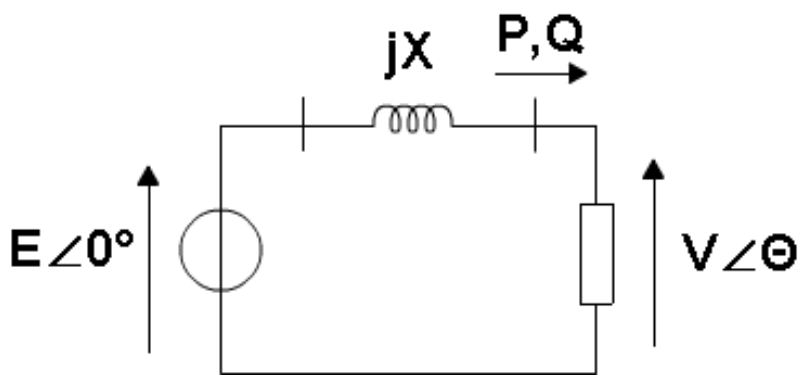

Fig. 1 Example grid with two busbars

For simplicity, the transmission line is taken into consideration only with its reactance. Power flow equations in the symmetrical case are

$P=\frac{E V}{X} \sin \theta$

$Q=\frac{V^{2}}{X}+\frac{E V}{X} \cos \theta$

where $P$ is the active, $Q$ is the reactive power of the load, $V$ is the voltage of the load and $\Theta$ is the angle difference between the generator's and the load's busbar voltage. By solving the above equations to $V$ we obtain

$$
V=\sqrt{\frac{E^{2}}{2}-Q X \pm \sqrt{\frac{E^{4}}{4}-X^{2} P^{2}-X E^{2} Q}}
$$

This equation determines the voltage change of the load as a function of the consumed active and reactive power. By plotting this function in $3 \mathrm{D}$ we can obtain loading limits for active power transmission. If we take the projection of this limit curve we obtain the so-called PV curves [1]:

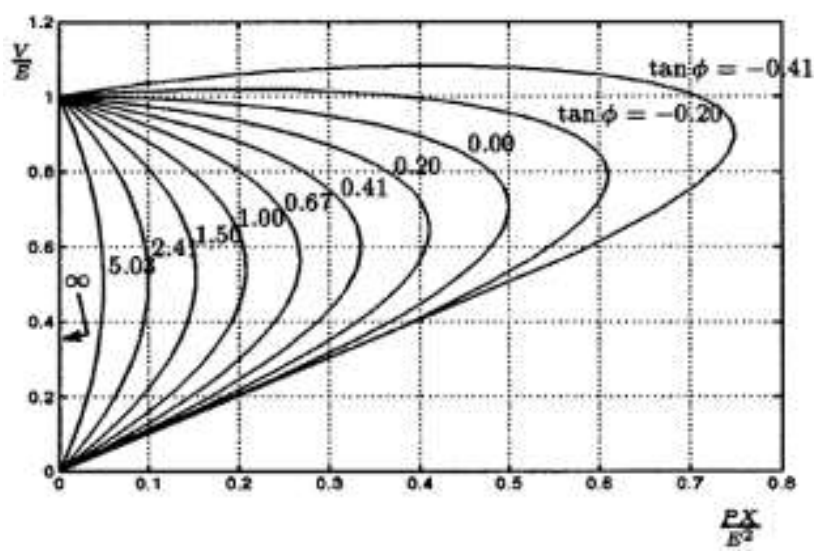

Fig. 2 PV curves [1]

The figure also depicts that the loadability limit depends on the $\tan \varphi$ of the load. We can observe maximum load points (so-called nose points): if the active power flow exceeds this value for a given $\tan \varphi$, the voltage will collapse. We can define voltage stability as the ability of a power system to maintain acceptable voltage at all buses under normal operation conditions and under contingency. We used these PV curves for voltage stability investigations in this paper.

\section{PV analysis}

To investigate the voltage stability of grids, we used the PV analysis tool of the simulation program PSS/E. PV analysis involves a series of load-flows with increasing active power transfer between a source and a sink while monitoring the voltage of every busbar in the grid. The source system in our case was all the $400 \mathrm{kV}$ generating units and the sink system was all the $120 \mathrm{kV}$ loads. The participation ratio of every generating unit in the source is the same $(33,3 \%)$, just as in the case of the loads in the sink $(4,76 \%)$. Later, we have changed these systems, depending on whether there is internal generation in the investigated system or not.

Before running the PV analysis tool, the system has to be initialized through a flat-start load flow: this sets the busbar voltages and power flows from which the PV analysis toolbox can calculate further. This case is defined as the base case. Active power transfer was increased during the PV simulation in 10MW steps compared to the base case: this increase we call transferred active power and will denote as such on the figures. We neglected the branch overloading thresholds (in fact, they were set to $200 \%$ to overcome the premature stopping of the PV analysis).

\section{The investigated grid}

Fig. 3. depicts the investigated grid: it is a 50-busbar system with $400 \mathrm{kV}$ (red), $220 \mathrm{kV}$ (green) and $120 \mathrm{kV}$ (blue) voltage levels. Nominal voltages in further sections are associated to these values.

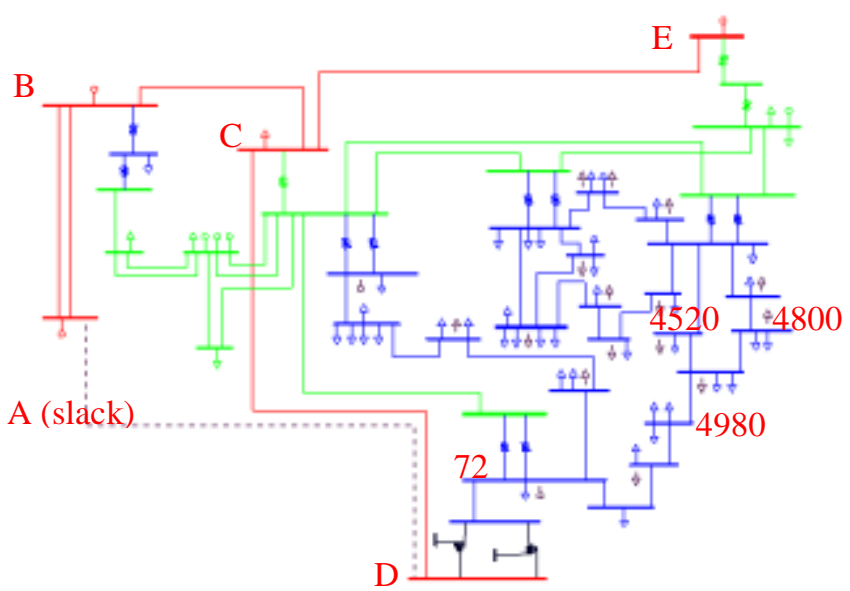

Fig. 3 The investigated grid 
The network is a meshed grid with low voltagepreserving capability: there are only a few generators in the grid and most of the $120 \mathrm{kV}$ busbars are electrically far from the generator busbars. $400 \mathrm{kV}$ infeeds represent outer generating sources, there is only one generating unit inside the grid (connecting to $220 \mathrm{kV}$ ). The dashed line between $\mathrm{A}$ and $\mathrm{D}$ represents a $400 \mathrm{kV}$ transmission line that is out of operation: we investigated in a later section how it would affect system stability if we turn this line on.

\section{Simulation results - with outer sources}

We have conducted several simulations to investigate the voltage preserving capability of the grid. We used PV analysis combined with contingency analysis. At first, there were no contingencies, i.e. no line or generator was tripped; then we investigated the effect of various contingencies on the voltage profiles of the $120 \mathrm{kV}$ busbars. For simulations in this section, all the outer generating units were activated.

\section{A. Simulations for the base case}

We first conducted simulations for the base case. By increasing the active power transfer between the source and the sink we obtained the following PV curves for various $120 \mathrm{kV}$ busbars:

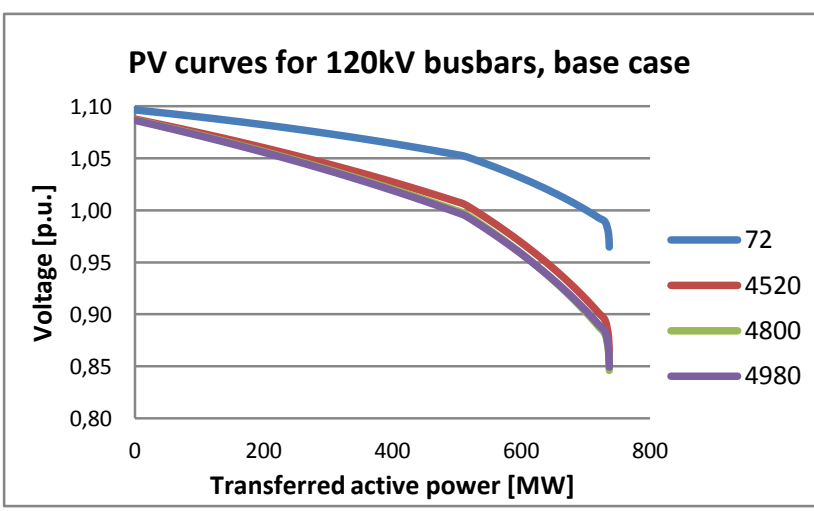

Fig. 4 Base case PV curves for various busbars

The figure shows that the initial load-flow results in 1.1 p.u. voltage at the source busbars, while at the nose point, sink busbar voltages decrease below 0.9 p.u. (that is $108 \mathrm{kV})$, which is unacceptably low. Depending on the electrical distance from busbars with voltage regulating capacity, the PV curves vary: busses that are electrically farther are more sensitive.

\section{B. Simulations with contingencies - 400kV source tripped}

The first investigated contingency is the tripping of a $400 \mathrm{kV}$ source (denoted with E on Fig. 3).

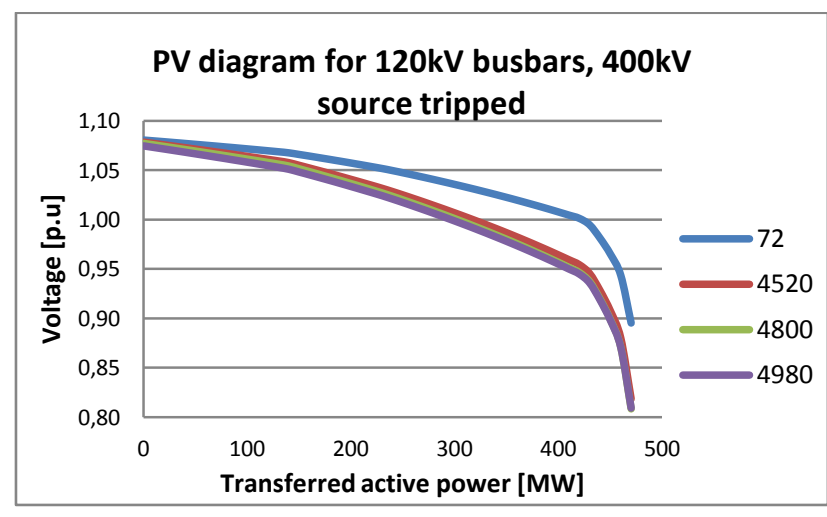

Fig. 5 PV curves for various busbars with $400 \mathrm{kV}$ generator tripping

Due to this tripping, a larger amount of active and reactive power is drawn from the slack bus (A), but as the system weakens, the active power that can be transmitted from source to sink decreases: by comparing Fig. 4. and Fig. 5. we can see that it is $736 \mathrm{MW}$ in the base case, while it is only $470 \mathrm{MW}$ in the case of contingency. On Fig. 6. we compare the obtained results for a transferred active power value where the PV curves for the case with contingency reach the nose points (in this case 470MW). We can see that the contingency results in smaller than 0,9 p.u., thus unacceptable voltages for most of the time.

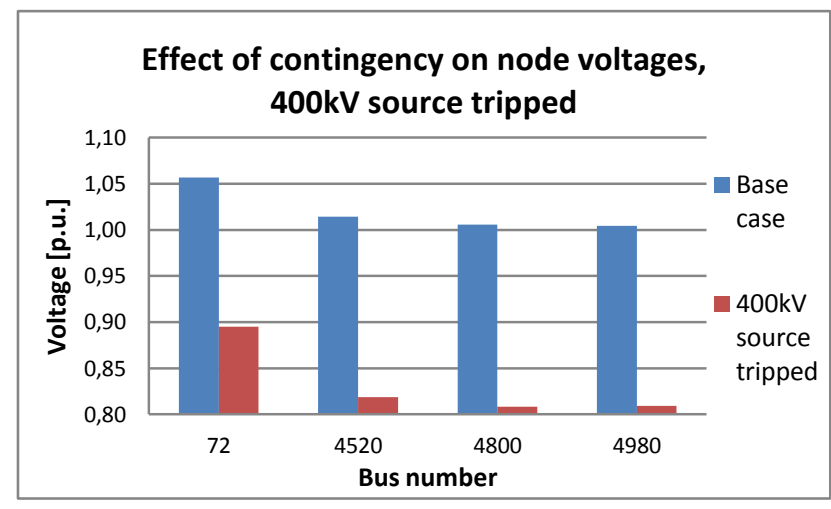

Fig. 6 Comparison of the minimum voltages for the case with and without contingency at 470MW transferred active power

\section{Simulations with contingencies - 400kV transmission} line tripped

The next investigated contingency is the tripping of a $400 \mathrm{kV}$ transmission line (C-D on Fig. 3). 


\section{Farkas, A. Faludi, T. Decsi \\ Static Voltage Stability Investigations on a Part of a Transmission Grid}

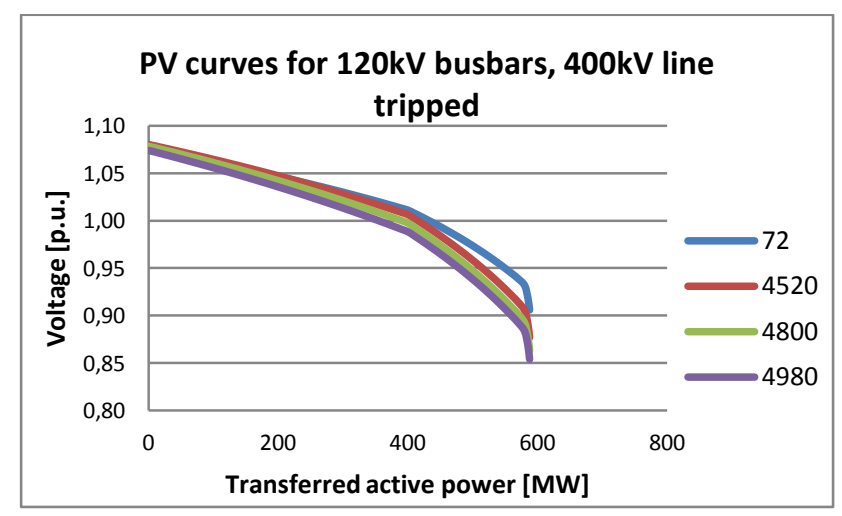

Fig. 7 PV curves for various busbars with $400 \mathrm{kV}$ line tripping

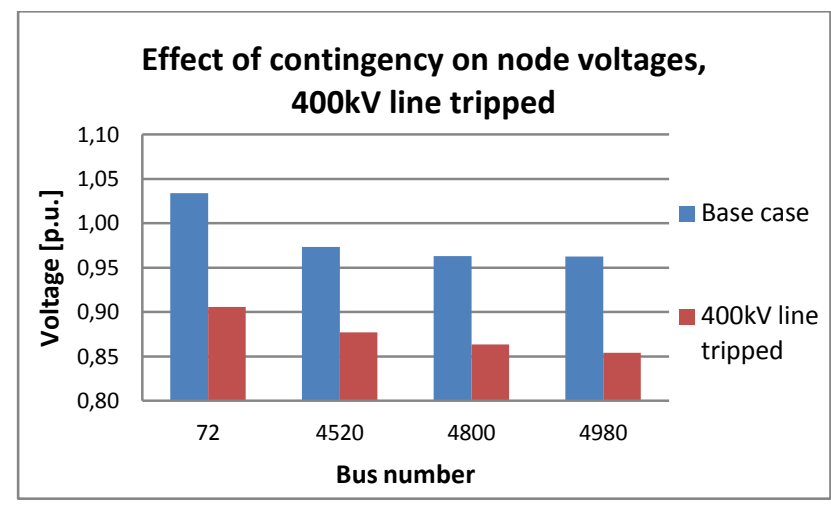

Fig. 8 Comparison of the minimum voltages for the case with and without contingency at 590MW transferred active power

We can compare the obtained results with the initial ones (see Error! Reference source not found..): again, we choose the nose points of PV curves in the contingency case (this time 590MW belongs to the nose point). Compared to Fig. 6. we can see that this contingency results in smaller voltage decrease compared to the contingency where a $400 \mathrm{kV}$ source was tripped.

\section{Investigation of $d V / d P$ values}

We have seen in the previous subsections that PV curves indicate the stability margin, but we obviously cannot wait until the voltage collapses: preemptive countermeasures have to be initiated before that. In order to be able to indicate that the system is close to voltage collapse, researchers have worked out various indices that are able to evaluate the system's state based on measuring voltages, voltage angles, powers, etc. (e.g. [2], [3], [4]).

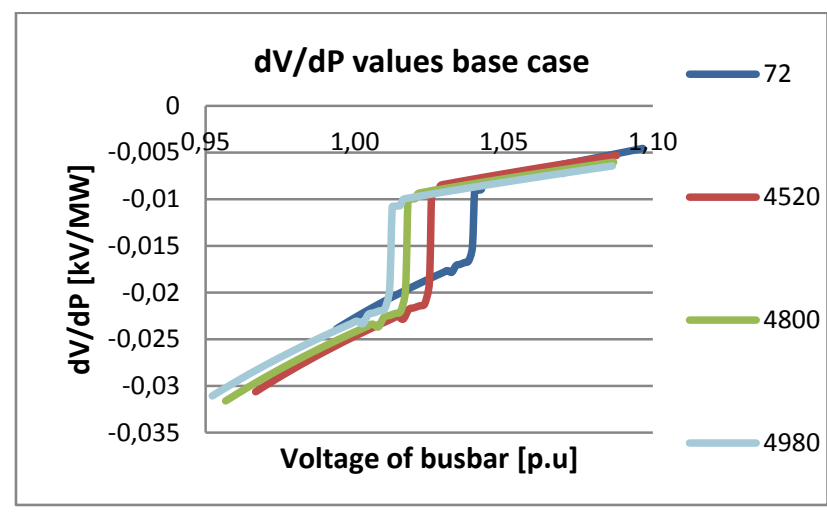

Fig. 9 dV/dP values for the base case for various busbars

Besides these indices, we investigated a method based on the gradient of the PV curves $(\mathrm{dV} / \mathrm{dP})$ for voltage instability detection. The required data for this index can be obtained from SCADA.

Previous figures indicate, that the gradients are not the same for the various curves, therefore we cannot use only the gradient: this is why we calculated what the voltages of the busbars are when we reach 10 times of the initial $\mathrm{dV} / \mathrm{dP}$ value (different from 10 times can also be chosen).

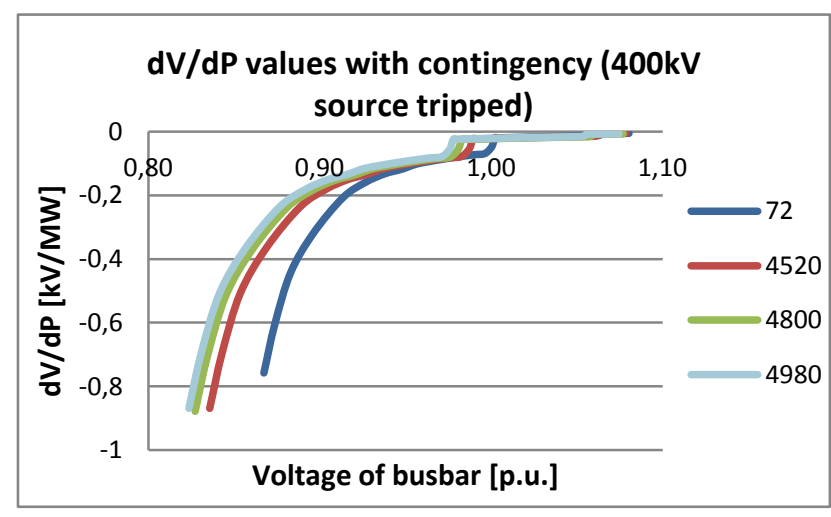

Fig. $10 \mathrm{dV} / \mathrm{dP}$ values when $400 \mathrm{kV}$ source $(\mathrm{E})$ is tripped

Fig. 9. and Fig. 10. show the dV/dP curves for the same busbars without and with contingency, respectively. We can see, that $\mathrm{dV} / \mathrm{dP}$ values change with system state, thus the curves alone cannot be used for prediction. Jumps can be seen in the curves: these are due to the $\mathrm{P}$ and $\mathrm{Q}$ limits of the generators - during PV simulations the set limits are reached and it affects the PV curves as well as the $\mathrm{dV} / \mathrm{dP}$ curves (without limits the curves become smooth).

Moreover, simulations show, that 10 times the initial $\mathrm{dV} / \mathrm{dP}$ values are rarely reached, only in cases with contingencies: but for these cases, the voltages when $\mathrm{dV} / \mathrm{dP}$ reaches the limit are between $84-90 \%$ of the nominal value, so the limit observations of $\mathrm{dV} / \mathrm{dP}$ values are promising in predicting when a system is getting closer to its voltage stability limit. Transmitted active power is $95-99 \%$ of the maximal when reaching the limit: 
this indicates that meshed $\mathrm{HV}$ grids remain stable even under stressed conditions. More simulations are required though, to test the capabilities of this index.

\section{E. Effect of additional $400 \mathrm{kV}$ line on voltage stability}

Fig. 3. shows that there is an additional, yet deactivated $400 \mathrm{kV}$ transmission line in the grid (A-D on Fig. 3). Turning it on has an effect on system stability, as depicted on Error! Reference source not found.. (the figure shows results for the base case).



Fig. 11 Effect of extra 400kV line on the PV curves (bus no. 4800)

It clearly shows that the increase in network complexity results in an improved voltage stability.

\section{Simulation results - without outer sources}

Next, we investigated what would happen, if there were no outer sources in the system. In this case, the source system is composed of the slack (which in fact does represent a kind of outer source) and a generator inside the system. Fig. 12. shows that there is no difference between the case when there is extra power coming from outer sources and when there is not. This means, that we can maintain busbar voltages in the system even in low reactive power generating cases. In Section 9. we will see that this, however has many consequences, such as an increase in losses.

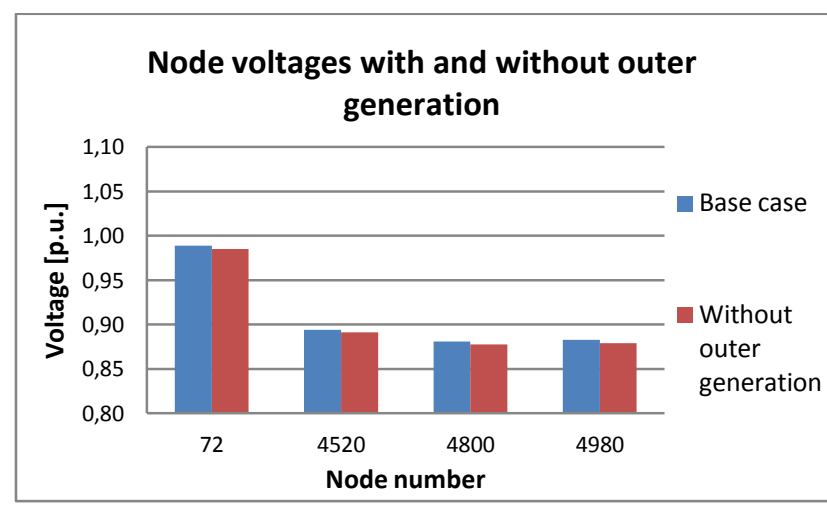

Fig. 12 Comparison of the minimum voltages for the case with and without contingency

\section{Results of PV analysis according to transformer tap ratio changes}

In this section we investigated the effect of the changing of transformer tap ratios on PV diagrams (see Fig. 13). Results are similar to the ones obtained in [5]. The investigated busbar (4980 on Fig. 3.) is electrically far from the generator busbars: this is why that despite there is a $20 \%$ change in the transformer tap ratio, the voltage changes only by $6 \%$ at $0 \mathrm{MW}$ transferred active power. We can observe that the shape of the PV curves remains the same at the different tap ratios, but they are shifted. We can also see that voltage reduction increases the voltage stability margin.



Fig. 13 PV curve shifting due to change in transformer tap ratio

\section{Voltage dependency of loads}

Table 1 Values describing voltage dependency of loads

\begin{tabular}{|c|c|c|c|}
\hline & $\mathrm{P}$ (const. power) & $\mathrm{I}$ (const. current) & $\begin{array}{c}\mathrm{Z} \text { (const. } \\
\text { impedance) }\end{array}$ \\
\hline $\mathrm{P}$ & $10 \%$ & $70 \%$ & $20 \%$ \\
\hline $\mathrm{Q}$ & $10 \%$ & $10 \%$ & $80 \%$ \\
\hline
\end{tabular}

We have also investigated how the voltage dependency of loads affects the obtained results.

In the previous simulations, loads were supposed to be 


\section{Farkas, A. Faludi, T. Decsi \\ Static Voltage Stability Investigations on a Part of a Transmission Grid}

constant power loads; now we use voltage dependent loads as shown in Table 1. The effect of modified load composition on the PV profile of a $120 \mathrm{kV}$ busbar that is far from the generator busbars (this time bus no. 4980; for other busbars, we obtained similar results) can be seen on Fig. 14. for the base case.

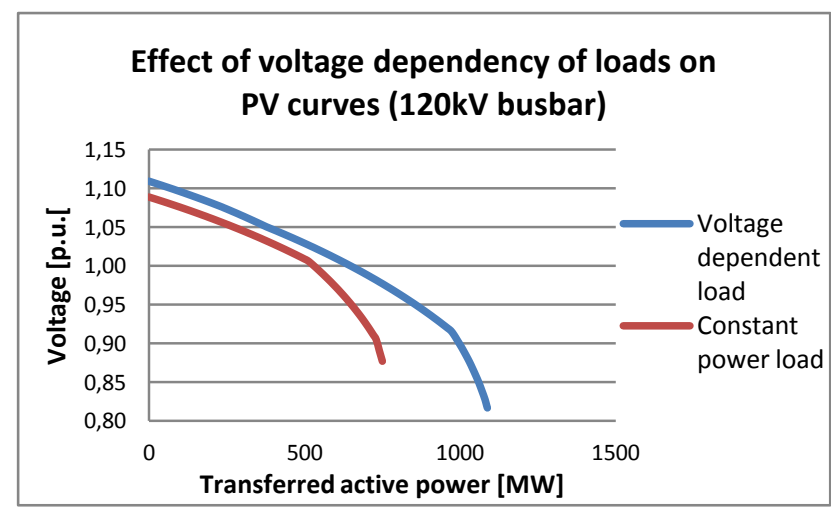

Fig. 14 Effect of different type of loads on PV curve

We can see that the purely constant power load results in smaller voltage stability limit, thus the results obtained with this model in the previous sections can be considered as the worst case.

\section{Effect of various system states on losses}

During normal operation conditions and even in the case when import was reduced, voltage stability could have been guaranteed for every busbar. This, however requires excessive reactive power transfer on the lines, which can result in increased losses. In this section, we investigate how contingencies affect system losses for normal and for stressed conditions. We summarize the results on diagrams. For easier comparison, the $\mathrm{x}$ axis runs to $470 \mathrm{MW}$ transferred active power on all the diagrams, though there might have been larger transfer in particular cases. Code was written in Python to calculate the losses, both aggregated and for individual lines.

\section{A. $400 \mathrm{kV}$ source $(E)$ tripped}

First we investigate the case when a $400 \mathrm{kV}$ source (E) is tripped. Fig. 15. and Fig. 16. show how the active and reactive power losses change when increasing active power transfer. Losses are doubled compared to the base case. In previous sections when the generator tripped, the PV analysis showed, that busbar voltages decreased only slightly, larger changes were observed only for excessive active power transfer between the source and the sink. This means, that although system stability can be maintained, system losses increase such, that it would be worth thinking about installing local generating capacities.

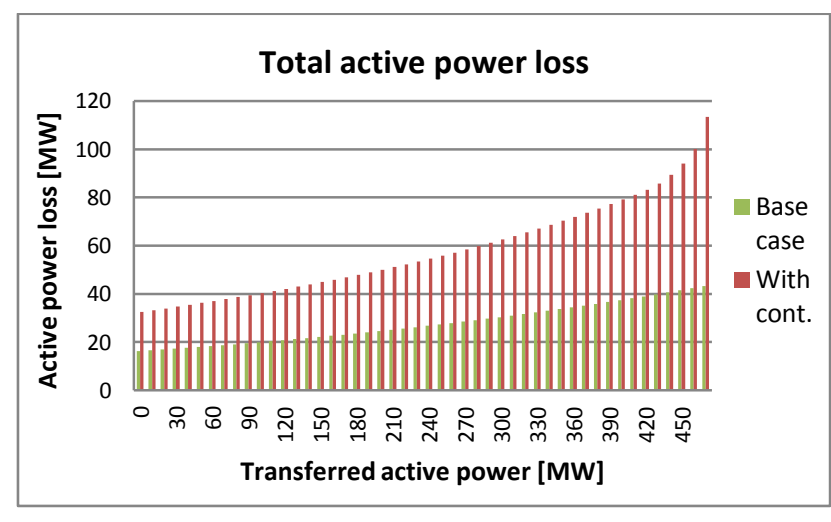

Fig. 15 Active power loss for the two cases for various active power transmission

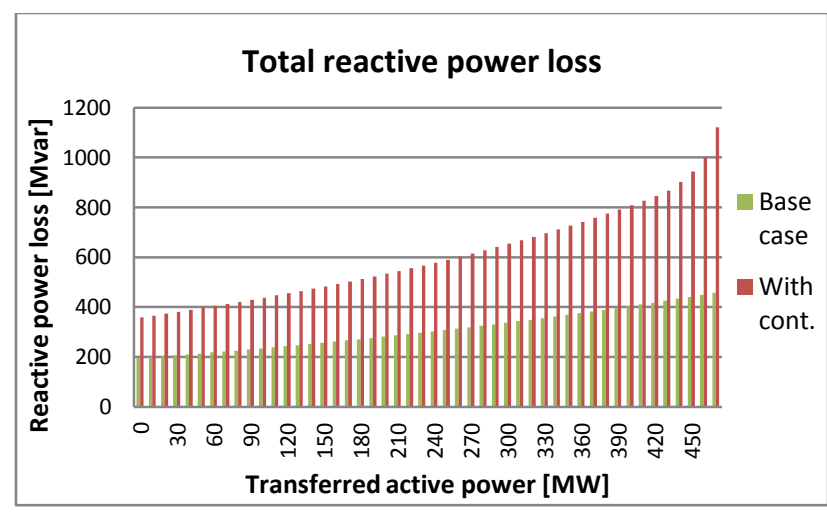

Fig. 16 Reactive power loss for the two cases for various active power transmission

\section{B. $400 \mathrm{kV}$ line tripped}

In the next case, a $400 \mathrm{kV}$ transmission line is taken out of operation: this weakens the grid, so increase in system losses is expected.

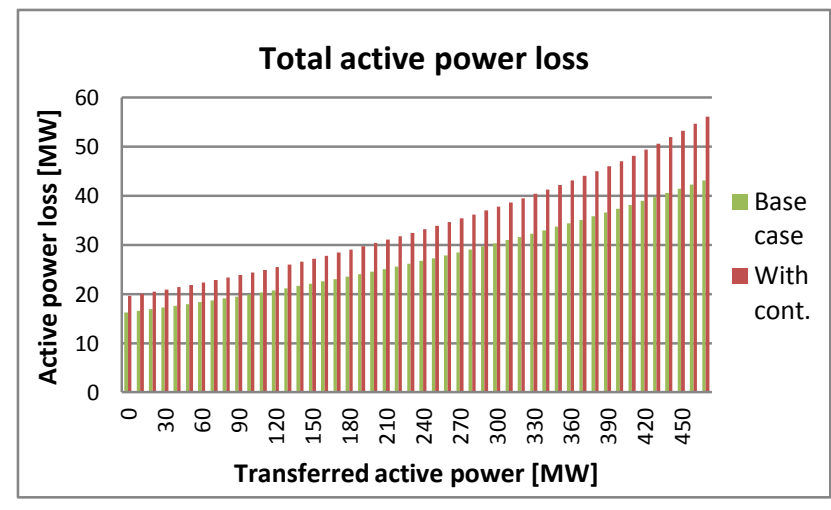

Fig. 17 Active power loss for the two cases for various active power transmission

Indeed, Fig. 17. and Fig. 18. show that both active and reactive power losses increase, however, the extent of increase is smaller compared to the case when a generator tripped. 


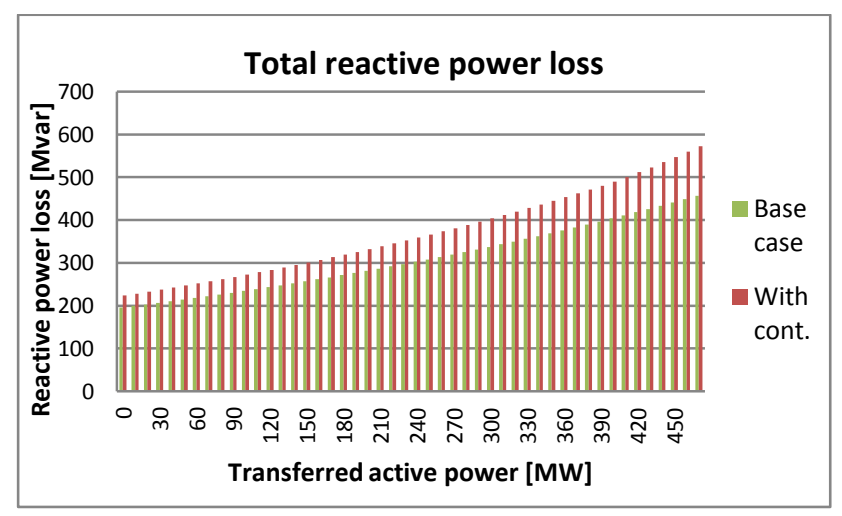

Fig. 18 Reactive power loss for the two cases for various active power transmission

\section{Planned further work}

Further work is planned to investigate the change of various busbar voltages during operation as a function of their short circuit power: as 3-phase short circuit power is different for every busbar (and in fact it characterizes the electrical distance of a given busbar from busbars with voltage preserving capability), we could create a boxplot that shows the variance of the voltages for these short circuit power values during a day.

\section{References}

[1] Thierry van Cutsem, "Voltage instability: phenomena, countermeasures and analysis methods", Proceedings of the IEEE, vol. 88., no. 2., February 2000. DOI: $\underline{10.1109 / 5.823999}$

[2] A. Tiranuchit, L.M. Ewerbring, R.A. Duryea, R.J. Thomas, F.T. Luk, "Towards a computationally feasible on-line voltage instability index", IEEE Transactions on Power Systems, vol.3., no. 2., May 1988., pp. 669-675. DOI: $\underline{10.1109 / 59.192921}$

[3] Juan Yu, Wenyuan Li, Wei Yan, Xia Zhao, Zhouyang Ren, "Evaluating risk indices of weak lines and buses causing static voltage instability", 2011 IEEE Power and Energy Society General Meeting, 24-29. July 2011., San Diego, USA, pp. 1-7. DOI: 10.1109/PES.2011.6038889

[4] Ismail Musirin, Titik Khawa Abdul Rahman, "On-line voltage stability based contingency ranking using fast voltage stability index (FVSI)", IEEE/PES Transmission and Distribution Conference and Exhibition 2002: Asia Pacific, 6-10. October 2002., pp. 1118-1123. DOI: 10.1109/TDC.2002.1177634

[5] Seon-Ju Ahn, Dong-Hyun Yoo, Joon-Ho Choi, "Impact of voltage reduction on voltage stability in emergency conditions", International Journal of Control and Automation, vol. 7., no. 4., (2014), pp. 65-72.

DOI: http://dx.doi.org/10.14257/ijca.2014.7.4.07 